NASA Contractor Report 179567

AIAA-87-0137

\title{
Effects of Droplet Interactions on Droplet Transport at Intermediate Reynolds Numbers
}

\author{
(NASA-CK-179567) EFFECTS CF LECELET \\ INIERACTIONS CN DEOPLET TEANSECEI AT \\ INTEEMEDIATE EEYNCIDS NOMEEES FiDaI \\ Ccntractor Refort ( $S v \in$ rdruf IEChnology, \\ Inc.) $20 \mathrm{p}$

Jian-Shun Shuen

Sverdrup Technology, Inc.

Lewis Research Center

Cleveland, Ohio

December 1986

Prepared for

Lewis Research Center

Under Contract NAS3-24105

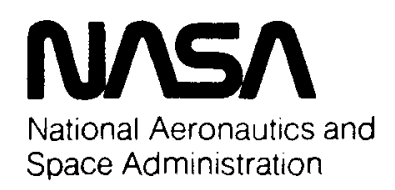


EFFECTS OF DROPLET INTERACTIONS ON OROPLET TRANSPORT AT INTERMEDIATE REYNOLOS NUMBERS

Jian-Shun Shuen

Sverdrup Technology, Inc.

Lewis Research Center

Cleveland, Ohio 44135

\section{Abstract}

Effects of droplet interactions on drag, evaporation, and combustion of a planar droplet array, oriented perpendicular to the approaching flow, are studied numerically. The threedimensional Navier-Stokes equations, with variable thermophysical properties, are solved using finitedifference techniques. Parameters investigated include the droplet spacing, droplet Reynolds number, approaching stream oxygen concentration, and fuel type. Results are obtained for the Reynolds number range of 5 to 100 , droplet spacings from 2 to 24 diameters, oxygen concentrations of 0.1 and 0.2 , and methanol and n-butanol fuels. The calculations show that the gasification rates of interacting droplets decrease as the droplet spacings decrease. The reduction in gasification rates is significant only at small spacings and low Reynolds numbers. For the present array orientation, the effects of interactions on the gasification rates diminish rapidly for Reynolds numbers greater than 10 and spacings greater than 6 droplet diameters. The effects of adjacent droplets on drag are shown to be small.

\section{Nomenclature}

B

$C_{D} \quad$ total drag coefficient

$C_{f} \quad$ friction drag coefficient,

$C_{f}=\frac{\text { total friction force }}{\frac{\pi d_{p}^{2} \rho_{\infty} q_{\infty}^{2}}{8}}$

Cp specific heat; pressure drag coefficient, $C_{p}=\frac{\text { total pressure force }}{\frac{\pi d_{p}^{2} p_{\infty} q_{\infty}^{2}}{8}}$

$D_{j} \quad$ mass diffusivity of species $i$ in the gas mixture

$d_{p} \quad$ droplet diameter

e total internal energy

f mixture fraction, defined as the mass originated from the droplets per unit mass of the gas mixture

$h \quad$ enthalpy; heat transfer coefficient

$h_{f g}$ heat of vaporization

$h_{f}^{0} \quad$ heat of formation

k thermal conductivity
M

$\mathrm{N}_{\mathrm{S}}$

$\mathrm{Nu}$

$\mathrm{p}$

$\operatorname{Pr}$

q

$r_{p}$

$\mathrm{R}_{\mathrm{e}}$

$\mathrm{Re}_{\mathrm{m}}$

$\grave{k}$

$\mathrm{S}$

T

$t$

u

v

w

$x$

$x, y, z$

Y

$\xi, n, \zeta$

$\theta$

$\mu$

v

$\rho$

$\tau$

A molecular weight

number of species

Nusselt number

pressure

Prandt? number

$\vec{u} \mathbf{u}$; heat flux

droplet radius

droplet Reynolds number, $R_{e}=\frac{\rho_{\infty} q_{\infty} d p}{\mu_{\infty}}$

droplet Reynolds number, $\operatorname{Re}_{m}=\frac{\rho_{\infty} q_{\infty} d_{p}}{\mu_{m}}$

universal gas constant

nondimensional droplet spacing, normalized by $d_{p}$

temperature

time

Cartesian velocity component in $x$ (axial)-direction

Cartesian velocity component in $y$-direction

Cartesian velocity component in z-direction

mole fraction

Cartesian coordinates

mass fraction

generalized curvilinear coordinates

oxygen concentration in the approaching stream; angle along the droplet surface measured from the front stagnation point

viscosity

stoichiometric coefficient (by mass) of oxygen

density

stress tensor

\section{Subscripts}

air property 
S droplet surface condition

stoic stoichiometric condition

UF unburned fuel property approaching flow condition

index of species

\section{Introduction}

The evaporation and combustion of liquid fuel sprays have received considerable attention. Much of the theoretical work has focused on the transport of single, isolated droplets. 1-3 In regions near the fuel nozzle, however, dense spray effects are important and droplets may evaporate and burn quite differently from those simulated in the isolated droplet approach. ${ }^{2-6}$ This is especially true for proposed advanced gas turbine combustion concepts, where liquid fuel and air are mixed in near stoichiometric proportions, in contrast to overall lean fuel/air ratios currently used in conventional combustors. The dense spray region is characterized ${ }^{2}$ by atomization, droplet interaction (defined here as modification of droplet transport rates due to the presence of adjacent droplets), droplet collision, coalescence, and breakup, change of turbulence properties by the droplets, the volume occupied by the liquid phase, etc. Droplet interactions are investigated numerically in the present study.

Previous theoretical studies on droplet interactions have largely been limited to droplets in arrays or clouds in the absence of forced convection (the diffusion theories), $5,7,8$ although Stefan flow induced by evaporation may be included in the analysis. Calculations of this type indicated that interactions can significantly reduce droplet evaporation and burning rates even for very large droplet spacings.7,8 For example, for an array of four burning droplets at spacing of 10 diameters, diffusion theory ${ }^{7}$ predicted that the droplet lifetime increased by 20 percent over the lifetime of a single, isolated droplet. For the same droplet spacing, in the presence of forced convection, the effects of interactions would be negligible, eyen for a droplet Reynolds number as 1 ow as two.9,10 Most investigators also adopted the constant property assumptions which resulted in predicted $f$ lame sizes exceeding the experimental values by factors of three to five. 1 Because larger flames compete more extensively for oxygen, the constant-property models predict much stronger interactions compared to the experimental data. ${ }^{6}$ Since most practical sprays involve appreciable droplet Reynolds numbers and large variations of thermodynamic and transport properties in the flow field, the constant-property diffusion theories appear to have limited utility in the analysis of droplet interactions in combusting fuel sprays.

The present study considers droplet interactions in a steady-state situation in the presence of forced convection, covering Reynolds numbers of interest for practical sprays, by solving the three-dimensional Navier-Stokes equations for flows through droplet arrays. The arrays considered are monosized, planar, semi-infinite, with array-planes perpendicular to the approaching flow direction. (Another array orientation of practical importance, i.e., droplets arranged in tandem along the flow direction, is not considered in the present study.) To better simulate the flow around droplets, variable gas properties are used in the analysis. Numerical results are obtained for Reynolds number range of 5 to 100 , droplet spacings of 2 to 24 diameters, approaching flow oxygen concentrations of 0.1 and 0.2 , and two types of fuel, methanol and n-butanol.

\section{Assumptions}

The equations describing the flow include the conservation of mass, momentum, energy, and species for both the gas and the liquid phases. Additional constitutive relations are the equation of state and the thermodynamic and transport properties as functions of temperature, pressure, and species concentrations. In order to make the problem tractable and to avoid undue complications, the following assumptions are made:

(1) The gas-phase processes are quasi-steady, i.e., the gas phase adjusts to the steady state structure for the imposed boundary conditions at each instant of time. This assumption is justified by the large liquid/gas density ratio. Because of the density difference, the liquid-phase properties, e.g., the surface regression rate, surface temperature, and species concentrations, change at rates much slower than those of the gas-phase processes.

(2) Liquid-phase internal motion and transient heating are neglected. The droplet remains uniformly at the wet-bulb temperature, which is determined by balancing the heat transfer to the liquid and the latent heat of vaporization. For singlecomponent fuel at low or moderate ambient pressures, Law and Sirignano 11 have indicated that transient heating constitutes only a small fraction of total interphase energy transport after the initial 10 to 20 percent of the droplet lifetime.

Because of assumptions (1) and (2), the droplet size, spacing, and Reynolds number all remain at their initial values, and the transient heating effect is excluded from the analys is. The assumptions offer two very important advantages. First, the detailed flow field solutions within the liquid droplet become unnecessary, and the only interphase properties sought in the solution procedures are temperature (wet-bulb temperature) and pressure, from which other interphase boundary conditions (such as fuel vapor concentration) can be calcuiated. Second and more important, the parametric effect of individual factors affecting droplet interactions can then be studied, without complications caused by simultaneous change of more than one parameter and the history of evaporation.

(3) Phase equilibrium is maintained at the droplet surface. The fuel vapor concentration at surface is given by the saturated vapor pressure correlation for the pure liquid, e.g., the ClausiusClapeyron equation, at the wet-bulb temperature. Surface tension corrections are neglected. 
(4) Effects of thermal radiation, turbulence, and the Dufour and Soret effects are neglected.

The droplets are spherical in shape. The pressure of the approaching flow is maintained at $1 \mathrm{~atm}$ and the ambient gases have negligible solubility in the liquid phase. The effect of natural convection is neglected since the Grashof number is generally two orders of magnitude smaller than the Reynolds number for the flows considered in this study.

(5) Mass diffusion is represented by an effective binary diffusion 1 aw.

(6) The chemical reaction rates are much faster than the gas-phase transport rates such that combustion occurs at a thin flame sheet where fuel and oxygen meet in stoichiometric proportions. The combustion processes proceed to completion.

(7) The mass diffusivities of the combustion products and the fuel vapor are equal. Because of assumptions (6) and (7), the gas-phase species concentration field of the burning droplets can be described by one conserved scalar quantity, e.g., the mixture fraction (defined as the fraction of mass originated from the droplets).

(8) Effects of the wake instability are neglected. The onset of wake instability for solid particles in isothermal flow occurs at Reynolds number around 130 , which is greater than the maximum Reynolds number (100) considered in the present study. No information is available concerning Reynolds number for the onset of wake instability for vaporizing or burning droplets.

The above assumptions may become invalid at very low pressures (much below $1 \mathrm{~atm}$ ), near thermodynamic critical point of the fuel, for very small droplets (on the order of $1 \mu \mathrm{m}$ ), or in the presence of luminous flames.

\section{Analysis}

\section{Governing Equations}

The three-dimensional, unsteady Navier-Stokes equations are solved for the asymptotic steadystate flow field in droplet arrays. The equations are cast in conservation law form and solved using a finite-difference method. To enhance numerical accuracy and efficiency, coordinate mappings are employed which bring droplet surface and symmetric planes onto coordinate surfaces, and cluster grid points near the droplet surface. The governing equations, written in the generalized curvilinear coordinates $\xi(x, y, z), \eta(x, y, z)$, and $\zeta(x, y, z)$, are given as follows: 12

$$
\frac{\partial}{\partial t} \hat{q}+\frac{\partial\left(\hat{E}-\hat{E}_{V}\right)}{\partial \xi}+\frac{\partial\left(\hat{F}-\hat{F}_{V}\right)}{\partial \eta}+\frac{\partial\left(\hat{G}-\hat{G}_{v}\right)}{\partial \zeta}=0
$$

where

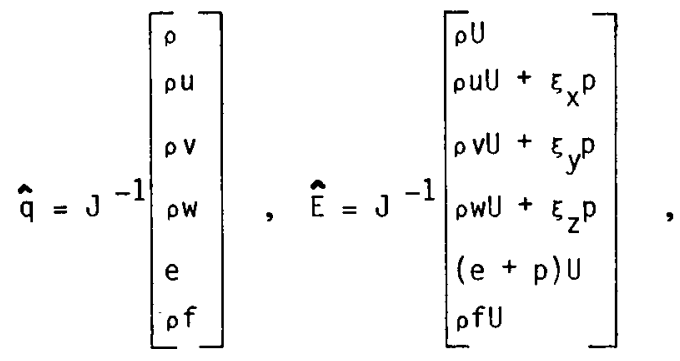

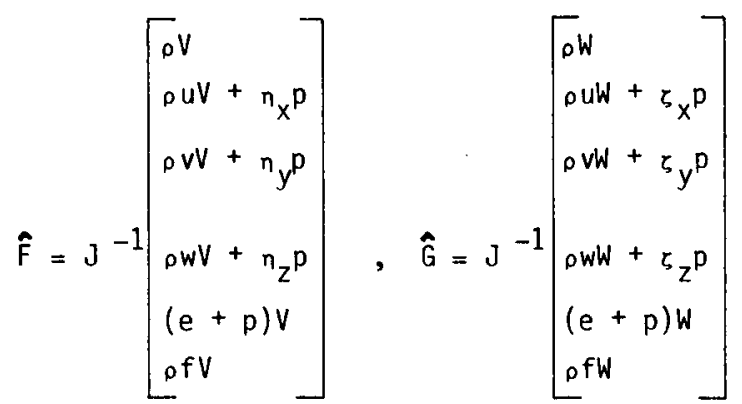

and

$$
\begin{aligned}
& U=\xi_{x} u+\xi_{y} v+\xi_{z} w, \\
& v=\eta_{x} u+\eta_{y} v+\eta_{z} w, \\
& w=\zeta_{x} u+\zeta_{y} v+\zeta_{z} w
\end{aligned}
$$

where $U, V$, and $W$ are contravariant velocities, $\xi_{x}, \xi_{y}, \xi_{z}$, etc. are the metric coefficients and $J$ is the Jacobian of the coordinate transformation.

The viscous flux terms are given by

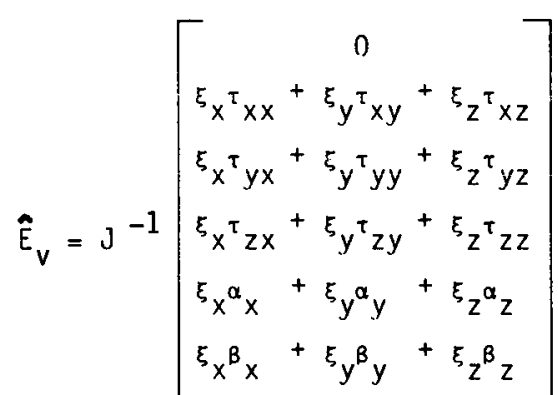

The forms for $\hat{F}_{v}$ and $\hat{G}_{v}$ are similar to $\hat{E}_{v}$, except $\xi$ is replaced by $n$ and $\zeta$ in $F_{V}$ and $\hat{G}_{y}$, respectively. 
The stress and viscous dissipation terms and the species and thermal energy diffusion terms are given by

$$
\begin{aligned}
& \tau_{x x}=2 \mu u_{x}-\frac{2}{3} \mu\left(u_{x}+v_{y}+w_{z}\right) \\
& \tau_{x y}=\tau_{y x}=\mu\left(u_{y}+v_{x}\right) \\
& \tau_{X z}=\tau_{z X}=\mu\left(u_{z}+w_{x}\right) \\
& \tau_{y y}=2 \mu v_{y}-\frac{2}{3} \mu\left(u_{x}+v_{y}+w_{z}\right) \\
& \tau_{y z}=\tau_{z y}=\mu\left(v_{z}+w_{y}\right) \\
& \tau_{z z}=2 \mu w_{z}-\frac{2}{3} \mu\left(u_{x}+v_{y}+w_{z}\right) \\
& \alpha_{x}=-q_{x}+u_{\tau_{x x}}+v_{\tau_{x y}}+w_{\tau_{x z}} \\
& \alpha_{y}=-q_{y}+u \tau_{y x}+v \tau_{y y}+w \tau_{y z} \\
& \alpha_{z}=-q_{z}+u \tau_{z X}+v_{\tau}+w_{z X} \\
& { }^{B} x=\mathscr{D}_{F} f_{x} \quad, \quad B_{y}=\mathscr{D O}_{F} f_{y} \quad, \quad B_{z}=\rho \mathscr{D}_{F} f_{z} \\
& q_{x}=-k T_{x}-\sum_{i=1}^{N_{S}} h_{i}{ }^{\circ} i^{Y} x \\
& q_{y}=-k T_{y}-\sum_{i=1}^{N_{S}} h_{i} \rho_{i} y_{y} \\
& q_{z}=-k T_{z}-\sum_{i=1}^{N_{S}} h_{i}{ }^{\rho} i^{Y} z
\end{aligned}
$$

where the subscripts $x, y$, and $z$ denote differentiation in the respective directions. The total internal energy and pressure are given by

$$
\begin{gathered}
e=\sum_{i=1}^{N_{s}} \rho h_{i} Y_{i}-p+\frac{\rho}{2}\left(u^{2}+v^{2}+w^{2}\right) \\
h_{i}=h_{f i}^{0}+\int_{T_{R}}^{T} C p_{i} d T \\
P=\text { oR } R T_{i=1}^{N_{S}} \frac{Y_{i}}{M_{i}}
\end{gathered}
$$

where $h_{f j}^{o}$ is the heat of formation for species

$i$ at the reference temperature $T_{R}$. The Cartesian derivatives are to be evaluated in $\xi, n, \xi$ space via the chain-rule, for example

$$
T_{x}=\xi_{x} T_{\xi}+n_{x} T_{n}+\zeta_{x} T_{\zeta}
$$

Thermodynamic and Transport Properties

The specific heat, thermal conductivity, and viscosity for each species are determined by polynomials of temperature, such as,

$$
C p_{i}=A_{i}+B_{i} T+C C_{i} T^{2}+D_{i} T^{3}
$$

The coefficients of these polynomials are found in Ref. 13. The specific heat of the gas mixture is obtained by concentration weighting of each species. The thermal conductivity and viscosity of the mixture, however, are calculated using Wilke's law, 14' for example, the mixture viscosity is determined by

$$
\mu=\sum_{i=1}^{N_{s}} \frac{\mu_{i}}{1+\frac{1}{x_{i}} \sum_{\substack{j=1 \\ j \neq i}}^{N_{s}} x_{j} \varphi_{i j}}
$$

where

$$
\varphi_{i j}=\frac{\left[1+\left(\frac{\mu_{j}}{\mu_{j}}\right)^{\frac{1}{2}}\left(\frac{M_{j}}{M_{i}}\right)^{\frac{1}{4}}\right]^{2}}{2 \sqrt{2}\left[1+\frac{M_{i}}{M_{j}}\right]^{\frac{1}{2}}}
$$

The binary mass diffusivity for the fuel vapor in the ambient gas is obtained using the ChampmanEnskog theory in conjunction with the Lennard-Jones intermolecular potential-energy functions. Details of this method can be found in Ref. 14 .

\section{Combustion Model}

Both droplet evaporation and combustion are considered in the present study. For the burning droplet case, a mixing controlled combustion model is employed. Chemical reaction rates are assumed to be much faster than the gas-phase mixing rates, and the chemical reactions proceed immediately to completion when the fuel vapor and the oxidizer are mixed in stoichiometric proportions. If we further assume that the combustion products have the same binary mass diffusivity as the fuel vapor in the gas mixture, the flame front positions can be determined from the stoichiometric mixture fraction values. The concentrations of the unburned fuel vapor, combustion products, oxygen, and nitrogen (assuming the approaching flow is composed of only oxygen and nitrogen) can then be determined by the mixture fraction and the flame front location. Denoting the stoichiometric coefficient (by mass) of oxygen as $v$ and the oxygen mass concentration in the approaching flow as $\theta$, the stoichiometric mixture fraction value and the species concentrations in the gas mixture can be calculated from

$$
f_{\text {stoic }}=\frac{1}{1+\frac{v}{\theta}}
$$

from the droplet surface to the flame front

$$
\begin{aligned}
& {\left[Y_{\text {prod }}\right]=\theta(1-f)\left(1+\frac{1}{v}\right)} \\
& {\left[Y_{\mathrm{N} 2}\right]=(1-\theta)(1-f)} \\
& {\left[Y_{02}\right]=0 .} \\
& {\left[Y_{U F}\right]=1-\left[Y_{\text {prod }}\right]-\left[Y_{\mathrm{N} 2}\right]-\left[Y_{02}\right]}
\end{aligned}
$$


and from the flame front to the outer edge of the flow domain

$$
\begin{aligned}
& {\left[Y_{\text {prod }}\right]=f(1+v)} \\
& {\left[Y_{N 2}\right]=(1-\theta)(1-f)} \\
& {\left[Y_{U F}\right]=0 .} \\
& {\left[Y_{02}\right]=1-\left[Y_{\text {prod }}\right]-\left[Y_{\mathrm{N} 2}\right]-\left[Y_{U F}\right]}
\end{aligned}
$$

After the concentration field is obtained, temperatures and pressures are calculated from Eqs. (6) to (8), using Newton's iteration method.

\section{Surface Integra! Parameters}

Previous numerical and experimental studies on drag and heat and mass transport for isolated droplets in high-temperature flows are abundant. 15 Results from these studies are used to validate the analysis and the numerical method described in this paper. Since results were presented in the form of drag coefficients and Nusselt numbers for most of the existing studies, these integral parameters are also calculated in the present study to facilitate comparison.

The drag force on the liquid droplet consists of contributions from the viscous stresses, the pressure, and the momentum flux at the interface. The computed momentum flux force (the thrust drag) at the droplet surface is about two orders of magnitude smaller than the other two forces and is therefore neglected. If grid orthogonality is maintained at the surface, the axial (approaching flow direction) component of the surface shear stresses. can be written, in terms of variables in the curvilinear coordinates $(\xi, n, \xi)$, as

$$
\begin{aligned}
F_{f} & =\mu \frac{\frac{\partial \hat{U}}{\partial \zeta}}{\sqrt{g} \hat{g}_{\zeta \zeta}}+\frac{\frac{\partial \hat{W}}{\partial \xi}}{\sqrt{g_{\xi \xi}}} \\
& +\frac{\frac{\partial \hat{U}}{\partial \eta}}{\sqrt{g_{\eta \eta}}}+\frac{\frac{\partial \hat{V}}{\partial \xi}}{\sqrt{g_{\xi \xi}}} \frac{x_{\xi}}{\sqrt{g_{\xi \xi}}} \\
& +\mu \frac{\frac{\partial \hat{W}}{\partial \zeta}}{\sqrt{g_{\zeta \zeta}}}-\frac{2}{3} \Delta \frac{x_{\zeta \zeta}}{\sqrt{g_{\zeta \zeta}}}
\end{aligned}
$$

where

$$
\begin{gathered}
\hat{U}=\frac{U}{\sqrt{\xi_{x}^{2}+\xi_{y}^{2}+\xi_{z}^{2}}} \\
\hat{v}=\frac{v}{\sqrt{\eta_{x}^{2}+\eta_{y}^{2}+\eta_{z}^{2}}} \\
\hat{W}=\frac{W}{\sqrt{\zeta_{x}^{2}+\zeta_{y}^{2}+\zeta_{z}^{2}}} \\
g_{\xi \xi}=x_{\xi}^{2}+y_{\xi}^{2}+z_{\xi}^{2}
\end{gathered}
$$

and $\Delta=\left(\xi_{x} U_{\xi}+\xi_{y} V_{\xi}+\xi_{z} W_{\xi}\right)$

$+\left(n_{x} U_{n}+n_{y} v_{n}^{\xi}+n_{z} W_{n}^{\xi}\right)+\left(\zeta_{x} U_{\zeta}+\zeta_{y} V_{\zeta}+\zeta_{z} W_{\zeta}\right)$, is the rate of dilation.

The expressions for $g_{\eta \pi}$ and $g_{\zeta \zeta}$ are similar to $g_{\xi \xi}$.

The axial component of the pressure force is

$$
F_{p}=-p \frac{x_{\zeta}}{g_{\zeta \zeta}}
$$

Integrating over the droplet surface and nondimensionalizing with approaching flow quantities, the drag coefficient becomes

$$
\begin{aligned}
& C_{D}=\frac{1}{\pi R^{2} \frac{\rho U^{2}}{2}} \int_{\xi=1}^{\xi_{\max }} \int_{n=1}^{n_{\max }} \\
& \qquad\left(F_{f}+F_{p}\right) \sqrt{g_{\xi \xi} g_{n \eta}-g_{\xi \eta}^{2}} d \xi d \eta \\
& \text { where } \quad g_{\xi \eta}=x_{\xi} x_{y}+r_{\xi} \gamma_{\eta}+z_{\xi} z_{n}
\end{aligned}
$$

To be consistent with most of the published data, the Nusseit and Prandti numbers are calculated using the film properties, i.e.,

$$
\mathrm{Nu}=\frac{h_{\mathrm{p}}}{k_{\mathrm{m}}} \quad, \quad \mathrm{Pr}=\frac{\mathrm{C}_{\mathrm{Pm}_{\mathrm{m}} \mu_{m}}}{k_{\mathrm{m}}}
$$

where the subscript $m$ refers to the film condition defined by $\theta=1 / 2$ in the following equations

$T_{m}=\theta T_{S}+(1-\theta) T_{\infty} \quad$ for evaporating droplets

$T_{m}=\theta T_{S}+(1-\theta) T_{f l a m e}$ for burning droplets

$Y_{m}=\theta Y_{S}+(1-\theta) Y_{\infty} \quad$ for evaporating droplets

and

$Y_{m}=\theta Y_{S}+(1-\theta) Y_{f l a m e}$ for burning droplets

The heat transfer coefficient is given as

$$
h=\frac{\left(k \frac{\partial T}{\partial r}\right)_{S}}{\left(T_{-}-T_{s}\right)} \quad \text { for evaporating droplets }
$$

$$
h=\frac{\left(k \frac{\partial T}{\partial r}\right)_{s}}{\left(T_{f l a m e}-T_{S}\right)} \text { for burning droplets }
$$

where the derivative $\partial / \partial r$, for orthogonal grids at the surface, is given by

$$
\frac{\partial}{\partial r}=\frac{\frac{\partial}{\partial \zeta}}{\sqrt{g_{\zeta \zeta}}}
$$


Grid System. Semi-infinite planar arrays of equally spaced droplets are employed in the present study. A schematic of a typical array configuration is shown in Fig. 1. Because of the symmetric arrangement of droplets, only a $45^{\circ}$ sector, as indicated in Fig. 1 , needs to be considered in the computation. To enhance numerical accuracy and efficiency, coordinate mappings are used which bring droplet surface and symmetry planes onto coordinate surfaces, and cluster grid points near the droplet surface. This would also help the implementation of boundary conditions, since no interpolations are required at boundary surfaces. An 0-type grid, as shown in Fig. 2, is generated algebraically, with minimum radial spacing (in the physical domain) of 0.02 droplet radius, and the grids are stretched exponentially in the radial direction outward from the droplet surface. For clarity of presentation, much larger grid spacings near the droplet surface and fewer grid lines are shown in Fig. 2 than actually used in the calculations. The grid orthogonality is maintained at and near droplet surface so that the interphase heat and mass fluxes and the shear stresses can be more easily calculated. In the curvilinear coordinates the computational domain is rectangular parallelpiped with uniform grid spacing, which facilitates the use of standard unweighted differencing schemes and helps to maintain higher order numerical accuracy. Most of the calculations in the present study are performed using a 55 by 15 by 55 grid, in the axial (the approaching flow direction), azimuthal, and radial directions, respectively. Fifteen grid lines in the azimutha? direction are considered adequate for spatial resolution, since the flow domain (only $45^{\circ}$ ) and the gradients of flow properties are smaller in this direction than in the other two directions. The grid is reduced to 41 by 12 by 41 for the lowest Reynolds number case $(\operatorname{Re}=5)$ due to the numerical instability in the finer grid. One calculation for $\operatorname{Re}=100$ using a 65 by 18 by 65 grid is carried out and the solutions show negligible improvement over the results obtained using the 55 by 15 by 55 grid. Therefore, it may be concluded that the numerical solutions are relatively independent of the grid density.

\section{Finite-Difference Procedure}

The finite-difference scheme used for solving the governing equations is the delta-form implicit approximate factorization algorithm described by Beam and Warming. 16 Since this and other similar schemes are fully documented in the literature,12,16,17 only a very brief discussion of the numerical method will be given here. Because only the asymptotic steady state solutions are required, a first-order Euler implicit scheme is used to integrate the unsteady Navier-Stokes equations in time. The spatial derivative terms are approximated with fourth-order central differences. Fourth-order explicit and second-order implicit artificial dissipation terms are added to the basic central-differencing algorithm to control the nonlinear numerical instability. 18 Local time linearizations are applied to the nonlinear terms 16 and an approximate factorization of the threedimensional implicit operator is used to produce locally one-dimensional finite-difference operators.16,17 The resulting operators are block pentadiagonal matrices, and their inversion, although much easier than the unfactorized operators, accounts for the major portion of the total computational effort of the implicit scheme. To improve the numerical efficiency a similarity transformation 19 is employed, which diagonalizes the blocks in the implicit scheme and produces scalar pentadiagonal operators in place of the block operators.

\section{Boundary Conditions}

The boundary conditions are implemented explicitly. The velocity, temperature, static pressure, and species concentrations are specified for the approaching flow. At the downstream plane where the flow leaves the computational domain, flow properties are extrapolated from interior points except for the static pressure, which is set equal to the approaching flow value. These upstream and downstream boundary conditions are applied at a distance of 25 diameters from the center of the droplet. At the mid-planes between the droplets, symmetry conditions are applied. The droplet surface mass flux due to gasification is given by

$$
\rho U_{S}=-\rho \mathscr{D}_{F} \frac{\left(\frac{\partial Y_{F}}{\partial r}\right)_{S}}{\left(1-Y_{F S}\right)}
$$

and the gas velocity components at the surface are obtained accordingly. The pressure on the droplet surface is calculated with a normal momentum relation (obtained by combining the three momentum equations).12 The droplet surface temperature is taken as the wet-bulb temperature, which is obtained from the balance of the total heat transfer to the surface and the latent heat of vaporization and, therefore, is part of the solution. The surface fuel vapor concentration $Y_{F s}$ is obtained from the partial pressure of the saturated fuel vapor at the wet-bulb temperature, using the Clausius-Clapeyron equation. For the case of droplet evaporation (nonburning), the gas phase is considered as a binary mixture of fuel vapor and air, and the mixture fraction $f$ is equivalent to the fuel vapor concentration; hence, $f_{S}=Y_{F S}$ and $Y_{A S}=1-Y_{E S}$ at droplet surface. For burning droplets, the surface mixture fraction is calculated by

$$
f_{S}=Y_{F S}+f_{\text {stoic }}\left(1-Y_{F_{S}}\right)
$$

where $f_{\text {stoic }}$ is given by Eq. (12). Concentrations of the remaining specios at the surface are obtained using Eq. (13).

\section{Results and Discussion}

Calculations are first made for single, isolated solid particles and evaporating droplets, where the abundance of existing experimental and numerical data facilitates the validation of the analysis described in previous sections. The streamlines and isotherms for an isolated methanol droplet in a hot air stream at a temperature of $800 \mathrm{~K}$, a Reynolds number of 100 , and a pressure of $1 \mathrm{~atm}$ are shown in Fig. 3. There is a recirculation region (wake) formed behind the droplet and the reattachment point at the axis $(\theta=\pi)$ is located at 0.96 diameters from the rear stagnation point. The isotherms show steep gradients near the 
front stagnation point, indicating that the heat transfer rate is higher at the front half of the sphere. The locations of the reattachment points behind solid particles in isothermal flows are also calculated for Reynolds numbers ranging from 20 to 100 . The predictions (not shown here) agree very well with the calculations by Rimon and Cheng 20 and the experimental data quoted by the same authors. As an example, the present calculations show that the reattachment distance for a solid particle at $\operatorname{Re}$ of 100 was 0.92 diameter, compared to the value of about 0.90 diameter reported in Ref. 20.

The drag of isolated solid particles in isothermal flows, and the drag and heat transfer of isolated evaporating droplets in hot streams at a temperature of $1000 \mathrm{~K}$ are compared with the numerical results reported by Renksizbulut and Yuen. 15 The friction, pressure, and total drag coefficients are shown in Fig. 4, and the heat transfer results are shown in Fig. 5. The agreement between the present calculations and the results of Ref. 15 is very good. Since the numerical results in Ref. 15 correlate well with a wide range of experimental data, the present numerical results also are in good agreement with experimental data. Figures 4 and 5 also indicate that the standard drag law and the conventional empirical expressions for Nusselt number can be used for evaporating droplets in flows with large variations of transport properties, provided the proper film properties are chosen for evaluation of Reynolds number and the heat transfer number (B).

The favorable comparisons discussed above have demonstrated the validity of the present analysis and numerical procedures. Therefore, we can proceed with confidence with the calculations of the interacting droplets. The droplet assemblages considered are planar arrays of equally spaced monosized droplets. The arrays are oriented perpendicular to the approaching flow direction. In the following, the effects of interactions are presented as a gasification rate correction factor

$\pi=\frac{\text { rate of gasification of a droplet in an array }}{\text { rate of gasification of an isolated droplet }}$

The gasification rate correction factors for e vaporating (nonburning) methanol droplets are shown in Figs. 6(a) and (b) for $T_{\infty}=700 \mathrm{~K}$ and $1400 \mathrm{~K}$, respectively. As seen in Fig. 6, droplet interactions are only important for small spacings and low Reynolds numbers. They become negligible for spacings greater than about 6 diameters and Reynolds numbers greater than about 10. The present calculations show much weaker and shorter-ranged interactions than predicted by the diffusion theories, 7,8 where the effect of forced convection is not considered. A close inspection of the predicted flow field indicates that, in the presence of forced convection, temperature and concentration variations are contained in a thin boundary layer around the droplet, and the approaching stream conditions prevail outside this boundary layer. Since the boundary layer thicknes around the droplet is of the order of magnitude of one droplet diameter for the Reynolds numbers considered here, the effects of neighboring droplets on evaporation are not likely to be very significant for droplet spacings much greater than one diameter.
The results of Figs. 6(a) and (b) are very similar, except Fig. 6(b) shows slightly stronger interactions. The thicker thermal and concentration boundary layers and the stronger competition among neighboring droplets for thermal energy caused by the more intense evaporation at higher temperature are responsible for the increased interactions.

Law et a 1,1,6 have indicated that the flame size and the ambient oxygen concentration are the major factors that determine the extent of interactions of burning droplets. The flame shapes for single, isolated methanol and n-butanol droplets at $\operatorname{Re}=25$ are illustrated in Figs. $7(a)$ and (b), respectively. Two approaching flow oxygen concentrations, $i . e ., 0.1$ and 0.2 , are considered. Since the stoichiometric mixture fraction of n-butanol fuel is smaller than that of the methanol fuel, the flame size of the former is larger than the latter, especially near the wake where the high mixture fraction region extends to several diameters downstream of the rear stagnation point. The influence of oxygen concentration on flame size is also clear from the figures. The stoichiometric condition occurs farther away from the droplet surface for the lower oxygen concentration flow, yielding larger flame stand-off distance.

Another important aspect in droplet transport analysis is the evaluation of physical properties
for the gas mixture around the droplets. $1,6,15$ To illustrate the importance of physical properties, the gas-phase thermal conductivity, viscosity, and the product of density and fuel vapor mass diffusivity in the $\theta=90^{\circ}$ plane, normalized by the interphase properties, are plotted against radial distance in Figs. $8(a)$ and (b) for an iso1 ated droplet undergoing evaporation ( $\mathrm{Fig}$. 8(a)) or burning (Fig. 8(b)). The figures clearly show that, if physical properties are taken to be constant and evaluated at free stream (evaporation case) or flame (burning case) conditions, droplet transport rates will be significantly overestimated compared to the variable-property approach. Law et al. 1,6 have also pointed out that, for isolated droplets, because of constant property assumptions, theoretical predictions of the flame size consistently exceed the corresponding experimental values by factors of three to five.

The gasification rate correction factors for burning methanol droplets are shown in Figs. 9(a) and (b), for approaching flow oxygen concentrations of 0.1 and 0.2 , respectively. The interactions are stronger than the results shown in Figs. 6(a) and (b) for the evaporating droplets. This is attributed to the higher gasification rate due to the presence of the flame and the competition for oxygen by the neighboring flames in the burning case. Figure $9(\mathrm{a})$ also shows stronger interactions than those in Fig. 9(b), which can be explained on the basis of flame size in that the larger flame in lower oxygen concentration stream competes more vigorously for oxygen with neighboring $f l$ ames and tends to have stronger interactions. 6 It can be clearly seen in both Figs. 9(a) and (b) that, in contrast to the findings based on the diffusion theories, 7,8 the effects of interactions diminish rapidly for droplet spacings greater than 6 diameters and Reynolds numbers greater than 10 . The stronger and longer ranged interactions obtained 
by the diffusion theory are mainly due to the absence of the forced convection and the use of constant properties in the analysis.

The burning rate correction factors for n-butanol droplets are shown in Figs. $10(a)$ and (b). The differences between Figs. 10(a) and (b) are similar to those between Figs. 9(a) and (b), i.e., larger flame size in lower ambient oxygen case yields stronger interactions. Figures $10(a)$ and (b) show that, compared to Figs. 9(a) and (b), n-butanol droplets experience slightly stronger interaction effects than methanol droplets under same flow conditions. This can again be explained on the basis of flame size in that the larger flames of the n-butanol droplets (as shown in Figs. $7(a)$ and (b)) compete more vigorousiy for oxygen since they are physically closer than the smaller flames of the methanol droplets.

The effects of interactions on droplet drag are also investigated in the present study. The blockage of flow by the adjacent droplets accelerates the flow (venturi effect) and produces larger shear stresses as well as a larger wake, and thereby a slight increase in friction drag and pressure drag. The increase in drag due to the venturi effect, however, is somewhat mitigated by the reduction in the boundary layer viscosity due to the lower flow temperatures around the interacting droplets (resulted from the competition for thermal energy for the evaporating droplets and the larger flame stand-off distance for the burning droplets). The net result is an insignificant change of drag due to interactions.

\section{Conclusions}

In the present study, we have investigated the effects of droplet interactions on the drag and gasification rates of evaporating and burning droplet arrays. The arrays considered are planar, semi-infinite, and are composed of equal-spaced monosized droplets of same fuel type, with array planes perpendicular to the approaching flow direction. The following conclusions can be drawn.

1. The present analys is predicts less intense and much shorter-ranged interaction effects than those obtained using the diffusion theories. The difficulties with the diffusion theories lie in the fact that forced-convection and variable-property effects are neglected in the analysis. Since most practical sprays have appreciable droplet Reynolds numbers and involve large property variations, the present analysis appears to have more relevance in the consideration of droplet interactions compared to the diffusion theories.

2. The effects of droplet interactions are stronger for the type of fuels and ambient oxygen concentrations which allow for larger flame sizes and thereby more intense oxygen competition. In this case, low ambient oxygen concentration and the fuel with smaller stoichiometric fuel mass fraction are in favor of interactions.

3. The effects of droplet interactions on drag are small for the array configuration considered in the present study.

Arrays with droplets aligned in tandem along the flow direction are not considered in the present study. Since, for droplet Reynolds numbers encountered in practical sprays, the wake can extend to more than one droplet diameter downstream of the rear stagnation point and the wake flame is even longer, the interaction effects for tandem arrays are iikely to be significant and warrant further study.

\section{References}

1. Law, C.K., "Recent Advances in Droplet Vaporization and Combustion, "Progress in Enerqy and Combustion Science., Vol. 8, 1982, pp. 171-201.

2. Faeth, G.M., "Evaporation and Combustion of Sprays," Progress in Energy and Combustion Science, Vol. 9, 1983, pp. 1-76.

3. Sirignano, W.A., "Fuel Droplet Vaporization and Spray Combustion Theory, "Progress in Energy and Combustion Science, Vol. 9, 1983, pp. 291-322.

4. Sangiovanni, J.J. and Kesten, A.S., "Effect of Droplet Interaction on Ignition in Monodispersed Droplet Streams," Proceedings of the 16th International Symposium on Combustion," Cambridge, MA, August 1976, The Combustion Institute, Pittsburgh, 1977, pp. 577-590.

5. Chiu, H.H. and Liu, T.M., "Group Combustion of Liquid Droplets," Combustion Science and Technology, Vol. 17, 1977, pp. 127-142.

6. Xiong, T.Y., Law, C.K., and Miyasaka, K., "Interactive Vaporization and Combustion of Binary Droplet Systems," Proceedings of the 20th International Symposium on Combustion, pittsburqh, PA, Auqust 1984, The Combustion Institute, Pittsburgh, 1985, pp. 1781-1787.

7. Labowsky, M., "Calculation of the Burning Rates of Interacting Fuel Droplets, " Combustion Science and Technology, Vol. 22, 1980, pp. 217-226.

8. Marberry, M., Ray, A.K., and Leung, K., "Effect of Multiple Particle Interactions on Burning Droplets," Combustion and Flame, Vol. 57, Sept. 1984, pp. 237-245.

9. Soo, S.-L., Fluid Dynamics of Multiphase Systems, Biaisdell Pub. Co., wattham, MA, 1967.

10. Happel, J. and Brenner, H., Low Reynolds Number Hydrodynamics, 2nd Rev. Ed., Noor dhoff International Publishing Corp., Leiden, The Netherlands, 1973.

11. Law, C.K. and Sirignano, W.A., "Unsteady Droplet Combustion with Droplet Heating - II : Conduction Limit," Combustion and Flame, Vol. 28, 1977, pp. 175-186.

12. Pulliam, T.H. and Steger, J.L., "Implicit Finite-Difference Simulations of ThreeDimensional Compressible Flow, " AIAA Journal, Vol. 18, Feb. 1980, pp. 159-167.

13. Yaws, C.L., Physical Properties, McGraw-Hill Publishing Co., New York, 1977. 
14. Reid, R.C., Prausnitz, J.M., and Sherwood, T.K., The Properties of Gases and Liquids, 3rd Ed., McGraw-Hill PubTishing Co., 1977.

15. Renksizbulut, M. and Yuen, M.C., "Numerical Study of Droplet Evaporation in a HighTemperature Stream," Journal of Heat Transfer, Vol. 105, 1983, May 1983, pp. 389-397.

16. Beam, R.M. and Warming, R.F., "An Implicit Finite-Difference Algorithm for Hyperbolic Systems in Conservation-Law Form," Journal of Computational Physics, Vol. 22, Sept. 1976, pp. 87-110.

17. Pulliain T.H. and Steger, U.L., "Recent Improvements in Efficiency, Accuracy, and Convergence for Implicit Approximate Factorization Algorithms," AIAA 23rd Aerospace Sciences Meeting, Reno, Nevada, Jan. 1985, AIAA Paper $85-0360$.
18. Pulliam, T.H., "Artificial Dissipation Models for the Euler Equations," AIAA 23rd Aerospace Sciences Meeting, Reno, Nevada, Jan. 1985, AIAA Paper 85-0438.

19. Pulliam, T.H. and Chaussee, D.S., "A Diagonal Form of an Implicit Approximate-Factorization Algorithm," Journal of Computational Physics, Vo1. 39, Feb. 1981, pp. 347-363.

20. Rimon, Y. and Cheng, S.I., "Numerical Solution of a Uniform Flow over a Sphere at Intermediate Reynolds Numbers," Physics of Fluids, Vol. 12, May 1969, pp. 949-959. 


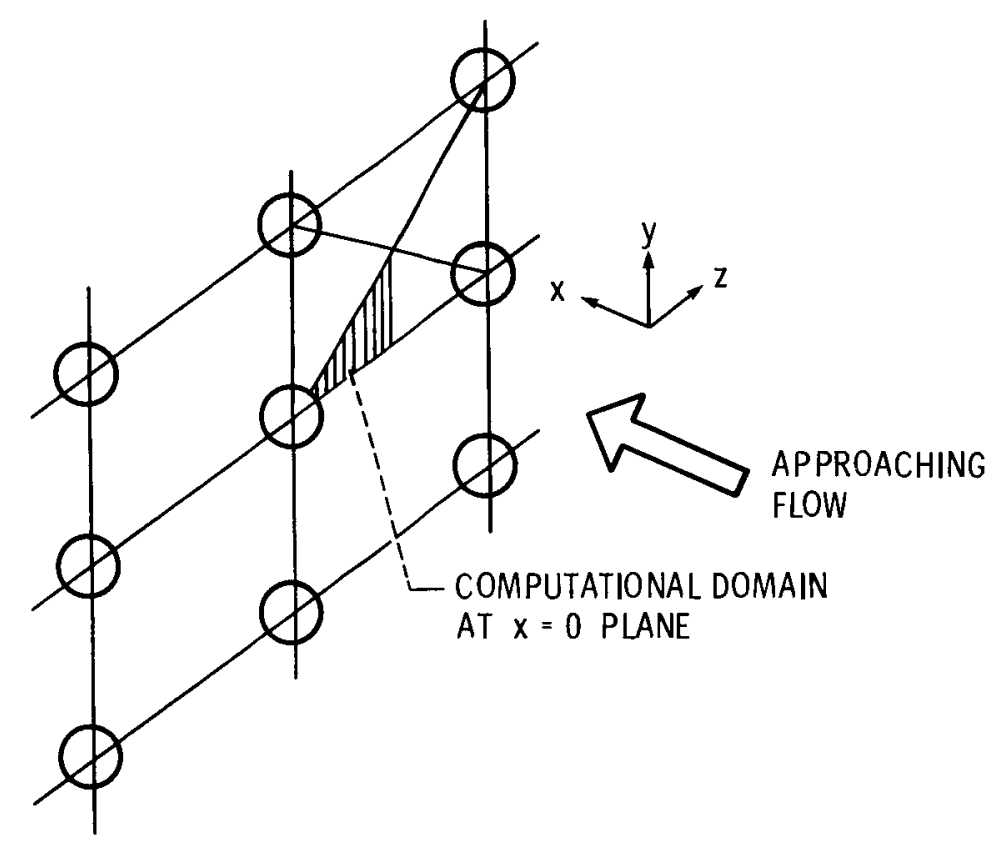

Figure 1. - Schematic of the semi-infinite droplet array. 


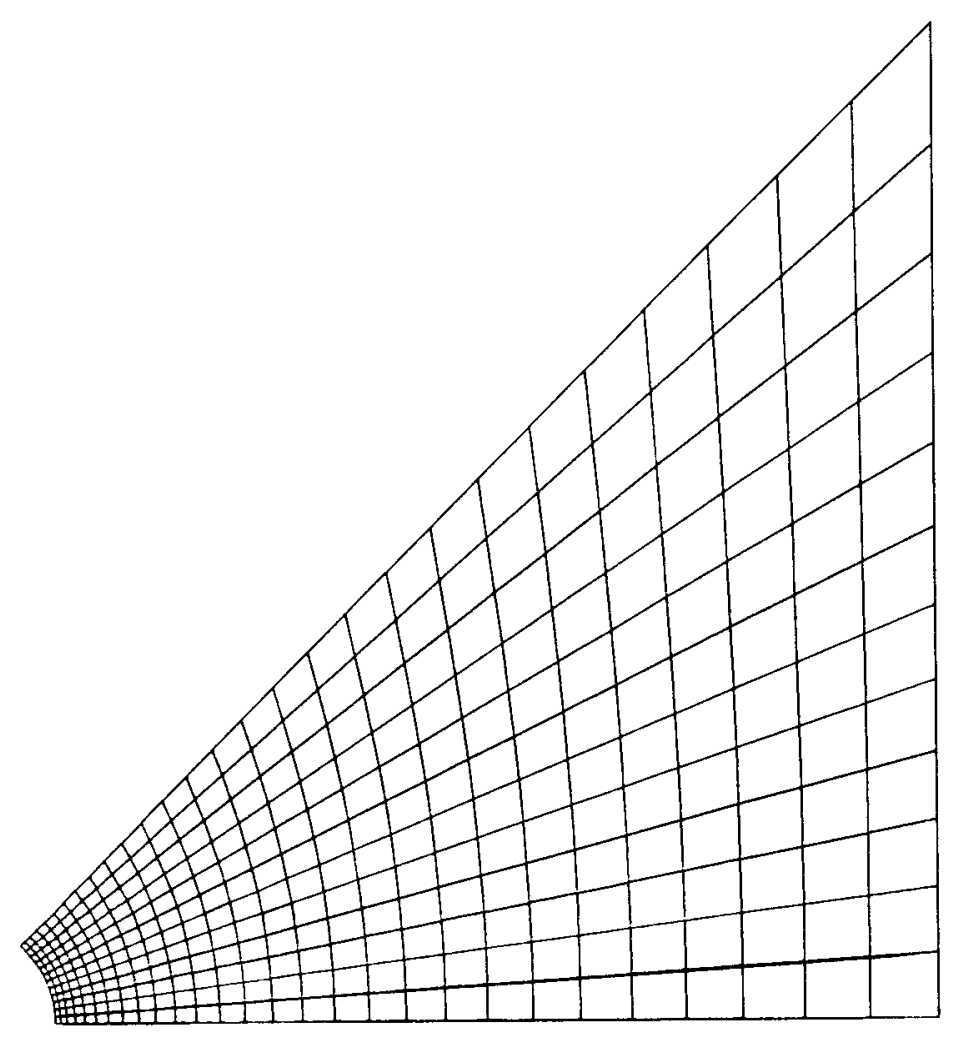

(a) Vertical plane $(x=0)$.

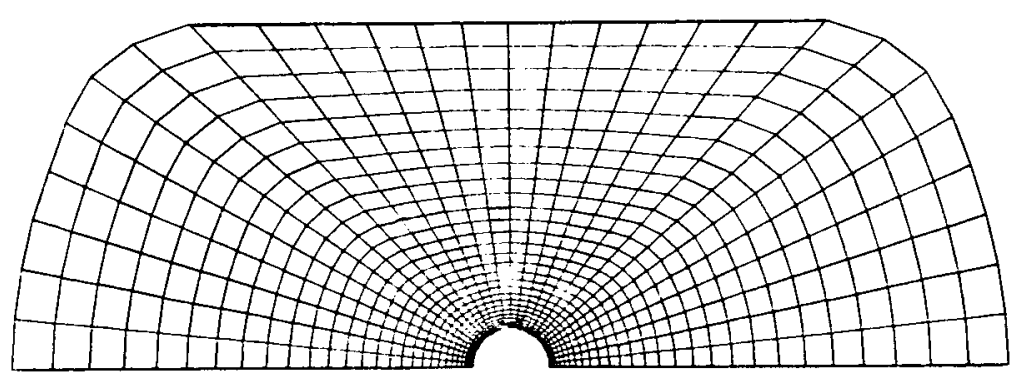

(b) Meridional plane $(y=0)$.

Figure 2. - Grid system. 


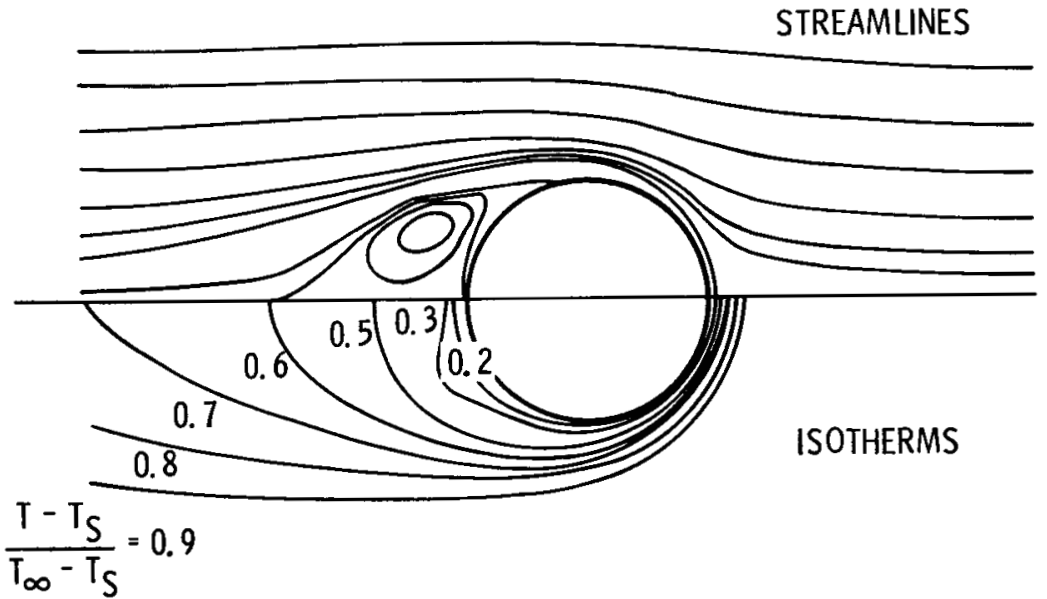

Figure 3. - Streamlines and isotherms of a vaporizing methanol droplet for $T_{\infty}=800 \mathrm{~K}$ and $\mathrm{Re}=100$ at meridional plane $(\mathrm{y}=0)$. 


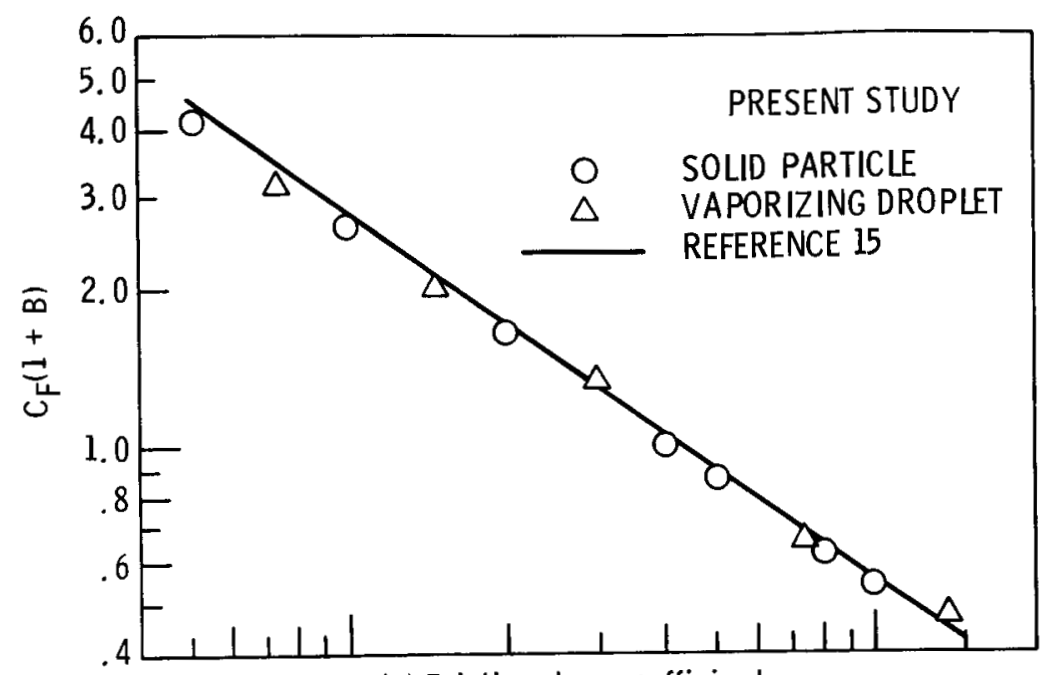

(a) Friction drag coefficient.

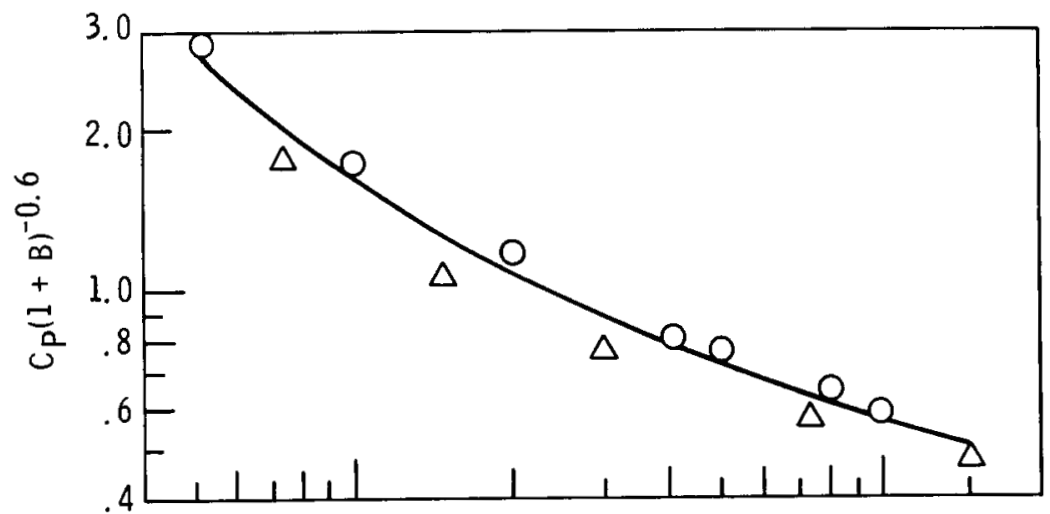

(b) Pressure drag coefficient.

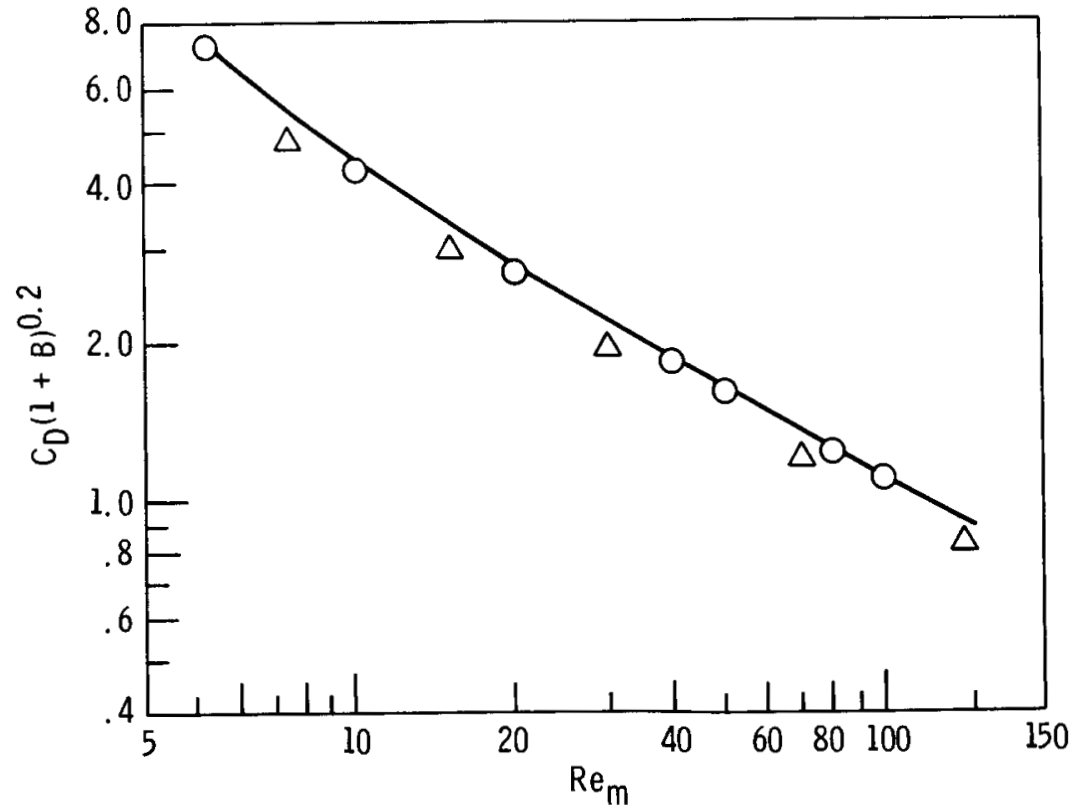

(c) Total drag coefficient.

Figure 4. - Drag coefficients for isolated solid particles and evaporating droplets. 


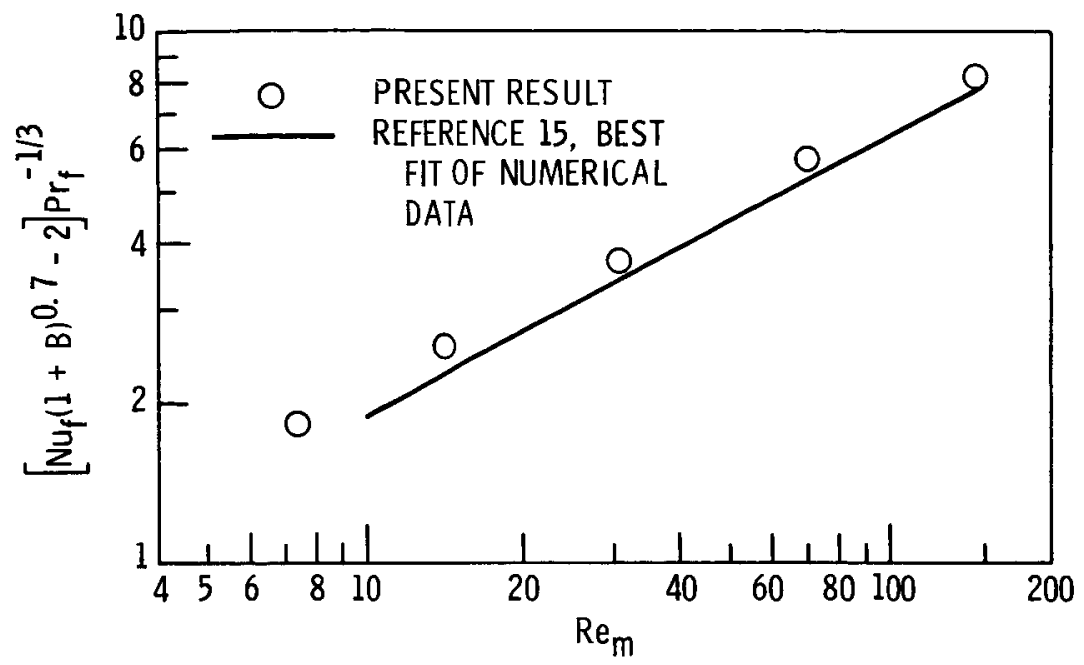

Figure 5. - Numerical heat transfer data for isolated evaporating droplets.

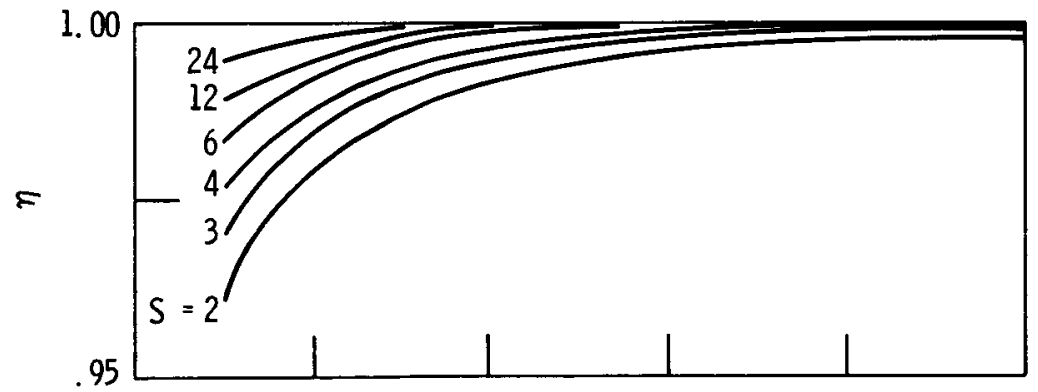

(a) $T_{\infty}=700 \mathrm{~K}$.

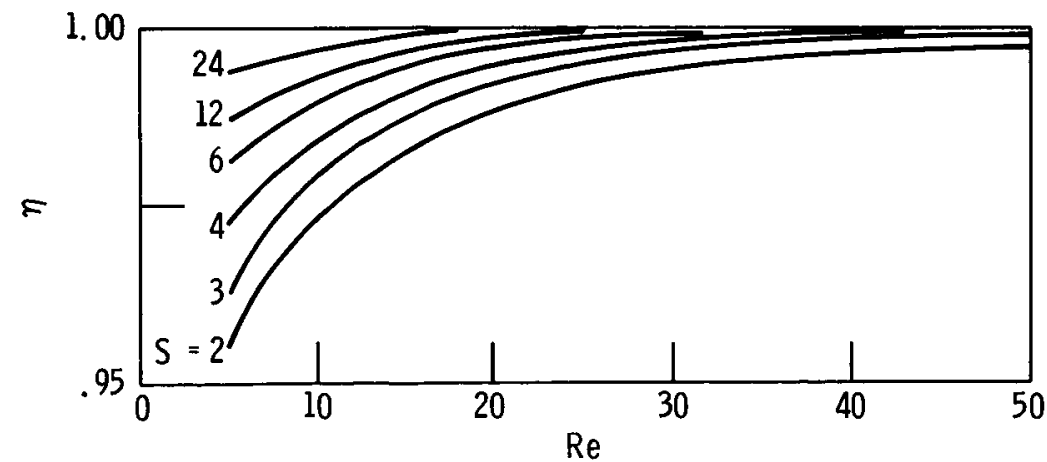

(b) $\mathrm{T}_{\infty}=1400 \mathrm{~K}$.

Figure 6. - Gasification rate correction factor for evaporating methanol droplets. 


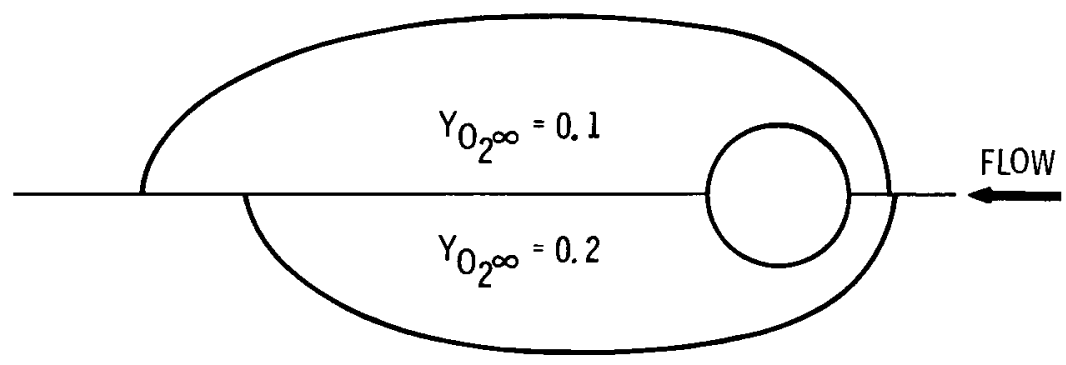

(a) Methanol droplet.

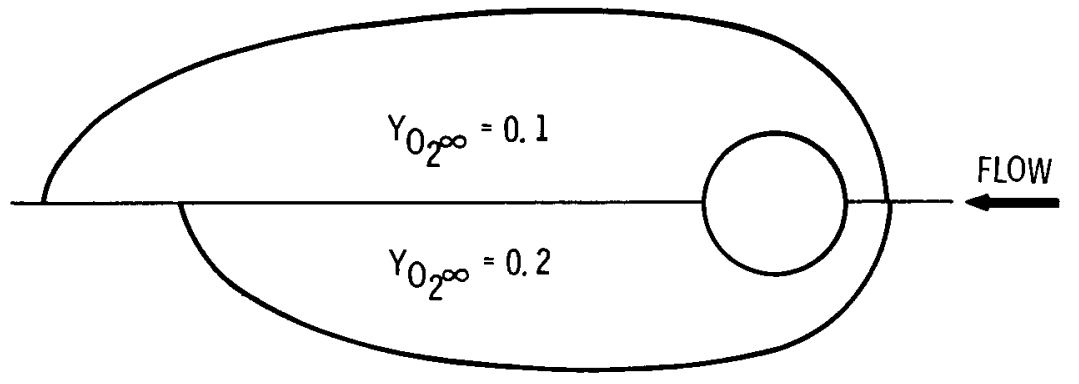

(b) n-Butanol droplet.

Figure 7. - Flame shape for isolated droplet at $R e=25$. 


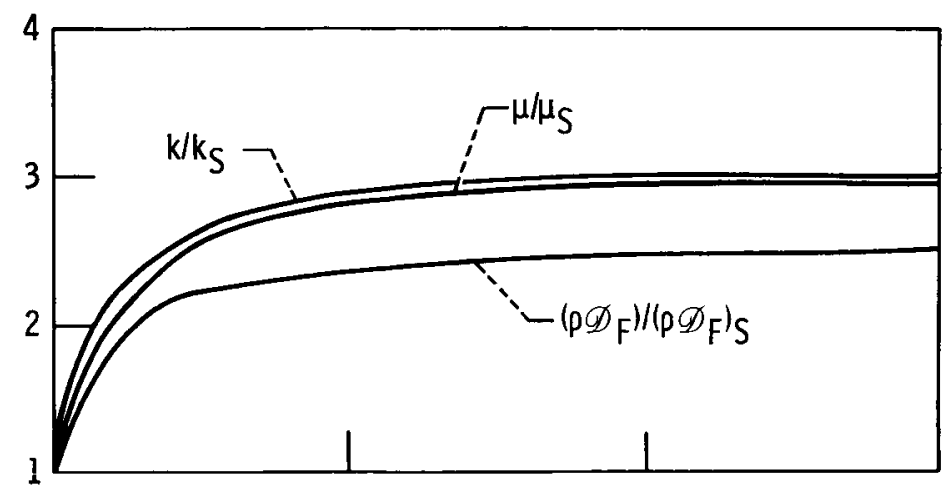

(a) Evaporating droplet, $T_{\infty}=1000 \mathrm{~K}$.

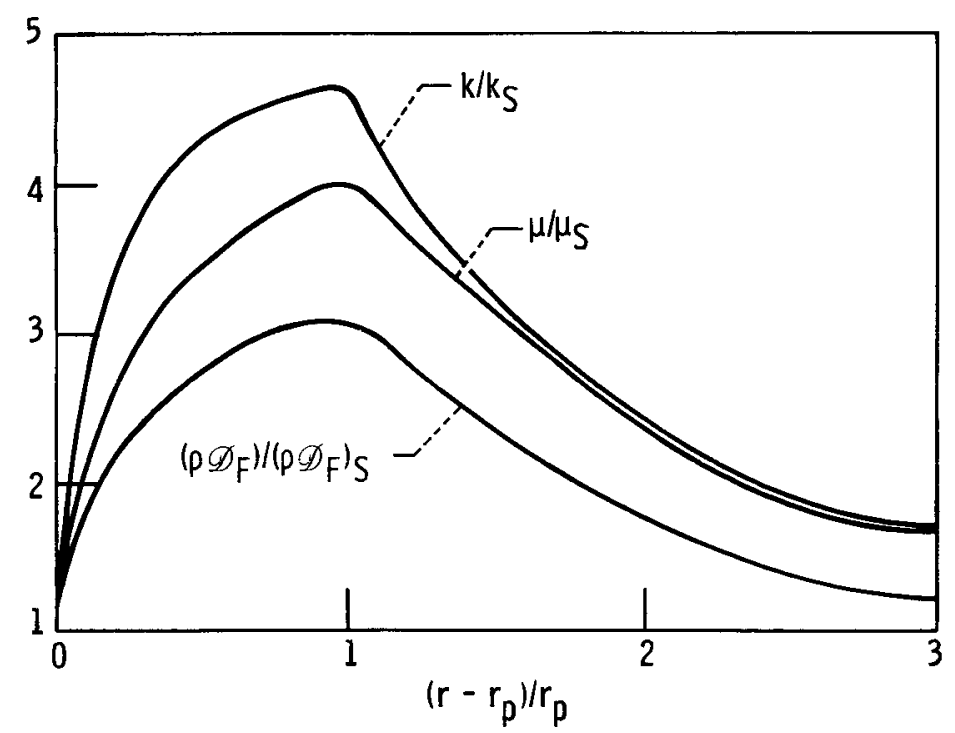

(b) Burning droplet, $\mathrm{Y}_{\mathrm{O}_{2}}=0.2, \mathrm{~T}_{\infty}=400 \mathrm{~K}$.

Figure 8. - Normalized gas mixture transport properties for isolated methanol droplet at $\theta=90^{\circ}$ plane, $R e=50$. 


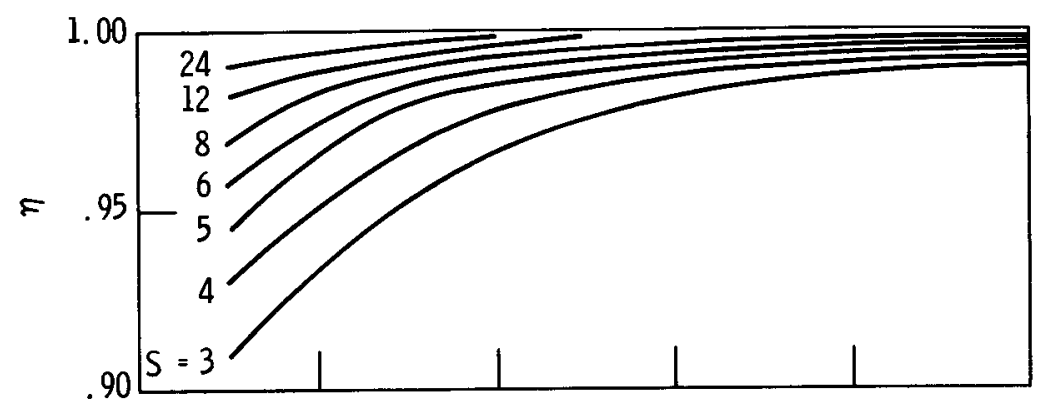

(a) $Y_{0_{2}}=0.1$

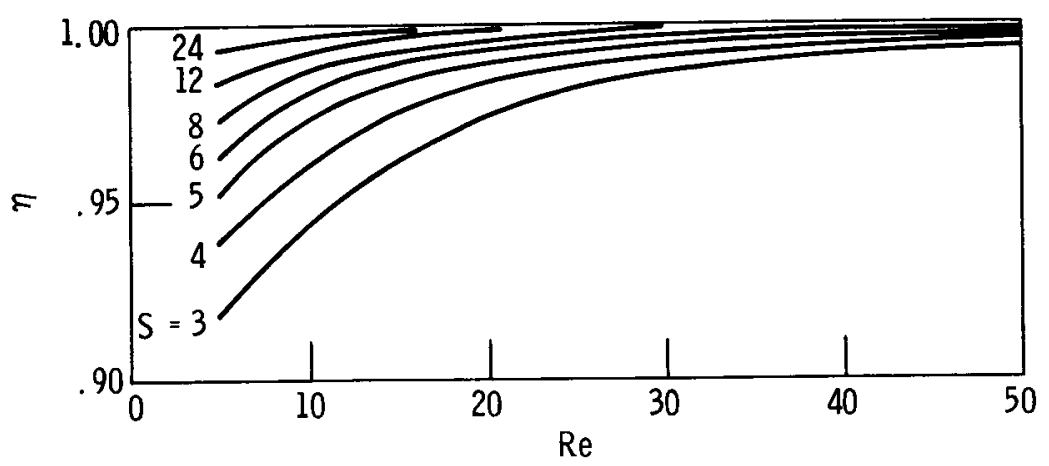

(b) $Y_{O_{2}}=0.2$

Figure 9. - Gasification rate correction factor for burning methanol droplets. 


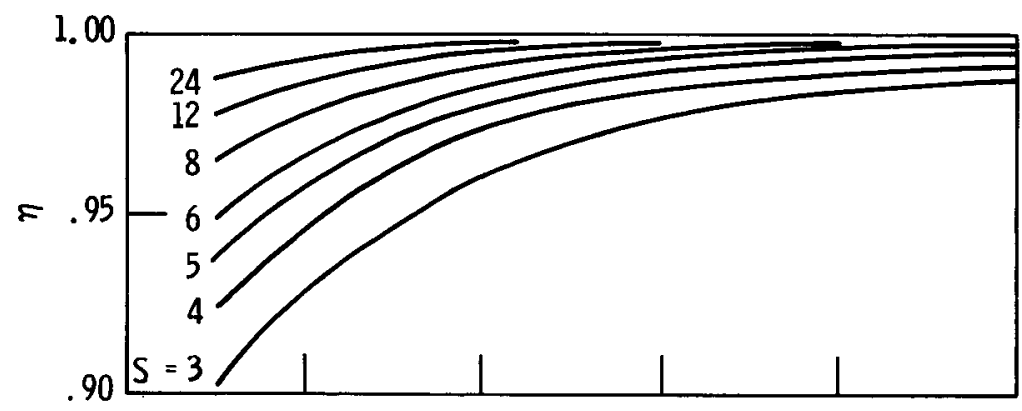

(a) $Y_{0_{2} \infty}=0.1$.

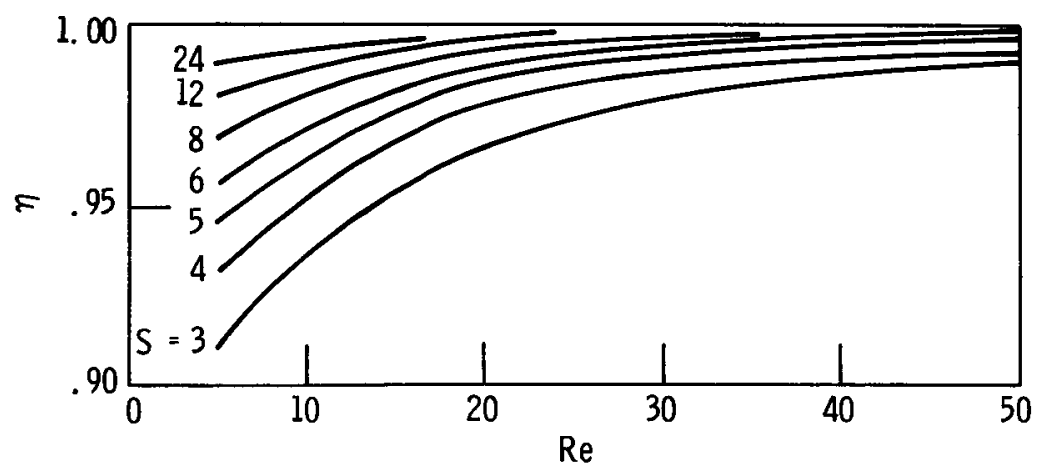

(b) $Y_{O_{2} \infty}=0.2$.

Figure 10. - Gasification rate correction factor for burning n-butanol droplets. 


\begin{tabular}{|c|c|c|}
\hline $\begin{array}{ll}\text { 1. Report No. } & \text { NASA CR-179567 } \\
& \text { AIAA-87-0137 }\end{array}$ & 2. Government Accession No. & 3. Recipient's Catalog No. \\
\hline \multicolumn{2}{|l|}{ 4. Title and Subtitle } & 5. Report Date \\
\hline \multirow{2}{*}{\multicolumn{2}{|c|}{$\begin{array}{l}\text { Effects of Droplet Interactions on Droplet Transport } \\
\text { at Intermediate Reynolds Numbers }\end{array}$}} & Decerimer 1900 \\
\hline & & 6. Performing Organization Code \\
\hline \multirow{2}{*}{\multicolumn{2}{|c|}{$\begin{array}{l}\text { 7. Author(s) } \\
\text { Jian-Shun Shuen }\end{array}$}} & $\begin{array}{l}\text { 8. Performing Organization Report No. } \\
\text { None (E-3293) }\end{array}$ \\
\hline & & $\begin{array}{l}\text { 10. Work Unit No. } \\
505-31-04\end{array}$ \\
\hline \multicolumn{2}{|c|}{$\begin{array}{l}\text { 9. Performing Organization Name and Address } \\
\text { Sverdrup Technology, Inc. } \\
\text { Lewis Research Center } \\
\text { Cleveland, Ohio } 44135\end{array}$} & $\begin{array}{l}\text { 11. Contract or Grant No. } \\
\text { NAS3-24105 }\end{array}$ \\
\hline \multicolumn{2}{|l|}{ 12. Sponsoring Agency Name and Address } & $\begin{array}{l}\text { 13. Type of Report and Period Covered } \\
\text { Contractor Report } \\
\text { Final }\end{array}$ \\
\hline \multicolumn{2}{|c|}{$\begin{array}{l}\text { National Aeronautics and Space Administration } \\
\text { Lewis Research Center } \\
\text { Cleveland, Ohio } 44135\end{array}$} & 14. Sponsoring Agency Code \\
\hline \multicolumn{3}{|c|}{$\begin{array}{l}\text { Project Manager, Daniel } \mathrm{L} \text {. Bulzan, Internal Fluid Mechanics Division, NASA Lewis } \\
\text { Research Center. Prepared for the } 25 \text { th Aerospace Sciences Meeting, sponsored by } \\
\text { the American Institute of Aeronautics and Astronautics, Reno, Nevada, } \\
\text { January } 12-15,1987 \text {. }\end{array}$} \\
\hline \multicolumn{3}{|c|}{ 16. Abstract } \\
\hline \multicolumn{3}{|c|}{$\begin{array}{l}\text { Effects of droplet interactions on drag, evaporation, and combustion of a planar, } \\
\text { droplet array, oriented perpendicular to the approaching flow, are studied numer- } \\
\text { ically. The three-dimensional Navier-Stokes equations, with variable thermo- } \\
\text { physical properties, are solved using finite-difference techniques. Parameters } \\
\text { investigated include the droplet spacing, droplet Reynolds number, approaching } \\
\text { stream oxygen concentratian, and fuel type. Results are obtained for the Reynolds } \\
\text { number range of } 5 \text { to } 100 \text {, droplet spacings from } 2 \text { to } 24 \text { diameters, oxygen concen- } \\
\text { trations of } 0.1 \text { and } 0.2 \text {, and methanol and n-butanol fuels. The calculations show } \\
\text { that the gasification rates of interacting droplets decrease as the droplet } \\
\text { spacings decrease. The reduction in gasification rates is significant only at } \\
\text { smali spacings and low Reynolds numbers. For the present array orientation, the } \\
\text { effects of interactions on the gasification rates diminish rapidly for Reynolds } \\
\text { numbers greater than } 10 \text { and spacings greater than } 6 \text { droplet diameters. The } \\
\text { effects of adjacent droplets on drag are shown to be small. }\end{array}$} \\
\hline \multicolumn{3}{|l|}{ 17. Key Words (Suggested by Author(s)) } \\
\hline \multicolumn{2}{|c|}{$\begin{array}{l}\text { Sprays; Droplet interactions; } \\
\text { Finite difference; Combustion; } \\
\text { Evaporation }\end{array}$} & $\begin{array}{l}\text { Unclassified - unlimited } \\
\text { STAR Category } 07\end{array}$ \\
\hline 19. Security Classif. (of this report) & $\begin{array}{l}\text { Security Classif. (of this page) } \\
\text { Unclas s if fed }\end{array}$ & \begin{tabular}{|l|l|} 
21. No. of pages & 22. Price* \\
\end{tabular} \\
\hline
\end{tabular}

